\title{
Unificación del Derecho Patrimonial Privado
}

\author{
Israel Creimer \\ Universidad de la República-Uruguay \\ creimer@adinet.com.uy
}

DOI: http://dx.doi.org/10.22235/rd.v0i14.123

1

Resumen: En este trabajo, el autor hace un análisis sucinto de la nueva tendencia codificadora, que vuelve a reunir el Derecho Civil y el Derecho Comercial. Su objetivo es demostrar la conveniencia de la unificación del Derecho Privado. Tiene en cuenta la reforma argentina, que entró en vigencia en agosto 2015, para repasar la normativa uruguaya.

Palabras Clave: derecho privado, recodificación, Código Civil y Comercial

SUMmARY: In this paper, the author does a succinct analysis of the new tendency, that goes back togather the Civil Right and the Commercial Right. His purpos is to show the suitability of the unification of the Private Right. It takes into account the Argentinian reform, that went in in force in August 2015, to review the Uruguayan rule.

KeYwORDS: private right, new codification, Civil and Commercial Code 

A Susie; sinellanadahubiera sidoposible

\section{PRELIMINARES}

Hace muchos años sostuvimos, en unas jornadas en la Asociación de Escribanos en homenaje al Prof. Cafaro, que éramos partidarios de la existencia de un único derecho pri- vado patrimonial. Esta idea se ratificó por escrito, en el año $2007^{1}$.

Por otra parte es indudable, que siempre habrá microsistemas jurídicos que se irán dando inevitablemente en el devenir del tiempo.

Con la presentación, de este trabajo, algo más extenso que el anterior, proponemos empezar un debate sobre la cuestión.

Sería bueno que otros se pronunciaran con sus comentarios, críticas o acuerdo con lo que se propugna. Creemos que el tema debe debatirse y resolver si la iniciativa es o no conveniente.

Alegría dice que los juristas tenemos "una misión, no necesariamente escrita de velar por el progreso del derecho dentro del marco de una sociedad cada vez más demandante de justicia y de igualdad"2.

1 Israel Creimer, “Obligaciones y Contratos Comerciales. Algunas observaciones complementarias generadas por el paso del tiempo", publicado en Estudios Jurídicos. № 3 (2007), 78.

2 Héctor Alegría, en sus palabras al recibir en 2013 su designación como Doctor Honoris Causa de la Facultad de Derecho de la Universidad de la República bajo el título: “Derecho Privado hoy y la innovación jurídica”. Revista de Derecho Comercial. Quinta Época, Año I, № 1 (Enero-Marzo, 2016), 120. 


\section{ANTECEDENTES}

En la Argentina, la tercera fue la vencida. Hubo dos proyectos de códigos unificados preparados por excelentes juristas, eliminando la dualidad de códigos: (civil y el comercial) y fracasaron.

El tercer proyecto, no demasiado diferente de los anteriores, finalmente entró en vi- gencia el 1ํo de agosto de 2015 Es una obra atractiva, que cambia sustancialmente el derecho positivo argentino y que, a esta altura, ya tiene un análisis doctrinario muy importante ${ }^{3}$.

Por razones históricas recibimos, muy al principio del siglo XIX, dos códigos france- ses: el de los civiles y el de la clase de los comerciantes.

El Derecho Comercial nació con las corporaciones post medioevales y se fue forjando por las necesidades de los mercaderes.

El Derecho Civil, con base romanística está pensado fundamentalmente para la con- tratación inmobiliaria.

El romano no era un derecho que regulara la circulación de bienes y servicios que los burgueses ofrecían en Ferias y Mercados. Los alfareros, herreros, peleteros, carpinteros y otros oficios se agrupaban en corporaciones. Ellas indicaban las normas técnicas del oficio y lo que, hoy llamaríamos, las relaciones laborales, las calidades de los productos y el derecho que regía sus actividades. Incluso tenían magistrados para resolver las controversias que se plantearan.

Con la llegada de la Revolución Francesa, que quiso romper el sistema corporativo medieval, no se quería conceder privilegios a una clase. Hubo que resolver este asunto para los comerciantes. De allí surge la idea del "acto de comercio" objetivo. El comerciante es quien realiza habitualmente estos actos. El listado de actos de comercio es anárquico y obe- deció a cuestiones prácticas. Eran los temas que estaban bajo la competencia de los jueces de comercio. Pero la actividad de este comerciante terminó subjetivizando a la clase de los comerciantes con normas que sólo se aplicaban a ellos ${ }^{4}$.

\footnotetext{
${ }^{3}$ Son innumerables los artículos y libros publicados. Debe señalarse especialmente el análisis exegético contenido en una vasta obra -Código Civil y Comercial de la Nación- cuyo director es Ricardo Lorenzetti, (Rubinzal-Culzoni Editores). También mencionaremos Código Civil y Comercial de la Nación Comentado, cuyos directores son Julio César Rivera y Graciela Medina, editado por La Ley. En ambos casos intervienen multiplicidad de juristas en los análisis del Código.

4 JulioC.Rivera, Código Civily Comercialdela Nación Comentado, 8.
} 
En definitiva, es por una razón histórica, no dogmática, que aparece un derecho comercial, distinto del civil. Tenemos dos regulaciones para los derechos privados patrimo- niales. Creemos que esto no se justifica.

Hace más de un siglo que se propugna la unificación de los códigos ya que, la existen- cia de dos, al menos en algunas partes, no parece razonable.

Broseta ${ }^{5}$ habló en forma elocuente en uno de los capítulos de su libro sobre el tema: "La progresiva generalización' de ciertas reglas e instituciones mercantiles, la unificación del Derecho de las obligaciones y la autonomía del Derecho Mercantil”. Afirma que se produce una poderosa transfusión de los actos mercantiles a quienes no son comerciantes, un robustecimiento de las actividades mercantiles en todas las clases sociales y por tanto un sometimiento de los actos objetivos a la competencia de los Tribunales Mercantiles. Existe una vasta corriente doctrinal, en el sentido de que el Derecho Mercantil ha dejado de ser subjetivo para convertirse en objetivo.

Esto produce "una creciente emigración de normas e instituciones nacidas en el Derecho Mercantil al Civil, la "progresiva y creciente difusión del espíritu comercial y que se comprueba una progresiva postergación de los contratos civiles por los mercantiles'"'. Cita en apoyo de sus afirmaciones a autores ilustres como Ascarelli, Ferrara, Garrigues yRipert.

En América Latina se han extendido bastante los códigos unificados.

En este trabajo exponemos los temas tratando de ser objetivos. Pero hay ideas que, inevitablemente, se inclinan por soluciones que se creen justas y adaptadas a nuestras actua- les circunstancias.

\section{¿CÓDIGOS?}

Hay una interrogante que, legítimamente, nos podemos hacer y es sí, a esta altura, es razonable la codificación. Esta supone una cierta estabilidad en el plexo normativo.

En la época en que vivimos, con cambios tan acelerados, ¿será conveniente cristalizar en códigos las normas que nos rigen?

El tema ha sido planteado por más de un autor. Entre nosotros, ha habido un pro- nunciamiento sobre esta cuestión: “A la decadencia de la organización económica liberal

\footnotetext{
5 Manuel Broseta Pont, La empresa, la unificación del derecho de las obligaciones y el derecho mercantil (Madrid, Tecnos, 1965), 198 y ss.

Revista de Derecho (UCUDAL). 2 da época. Año 10. Nº 14 (dic. 2016). ISBN 1510-3714. ISBN on line 2393-6193
} 
correspondió la destrucción' de su mayor creación jurídica: la noción de código como un sistema cerrado capaz de contener en si mismo la solución de todos los problemas jurídicos, sustentado sobre los principios de libertad e igualdad"6 Como muy bien lo señala López Rodríguez, la legislación moderna tiende a evadirse de los códigos.

Hemos visto que, desde hace décadas, el estatuto del Rematador salió del Código de Comercio, con una ley especial y luego, las cataratas de leyes recientes y no tan recientes, Títulos Valores, Mercado de Valores, Sociedades, Concursos, etc.

Está lejos de nuestra posición actual, la posibilidad de un Código multinacional, que propende a la uniformación del Derecho privado latinoamericano como se ha propuesto ${ }^{7}$.

El Prof. Arturo Caumont, en un trabajo reciente, reitera una posición que ha soste- nido desde hace tiempo. Afirma que la dispersión legislativa con leyes especiales, genera una falta de certeza que no es buena. En consecuencia, propone revertir la corriente de decodifi- cación a la recodificación.

Por supuesto, afirma como positivo el proceso de neoconcentralización por la vía de la unificación del Derecho Civil y el Derecho Mercantil. Cita, a favor de su posición una extensa bibliografía ${ }^{8}$.

En similar sentido De Cores en un trabajo que no refiere estrictamente a este tema, sino a la teoría general del contrato, ha dicho: "En una muy breve síntesis, puede afirmarse que en este último lapso hemos pasado por la experiencia de la decodificación y de la reco- dificación del derecho contractual y de la fragmentación, así como de la revalorización de la unidad de la teoría general del contrato"s

Luego analiza la posibilidad de una única teoría general: "La tesis de la fragmenta- ción sostiene que ya no existe una teoría general unitaria del contrato que, a partir de la sistemática clara del Código Civil, ejerza un imperio sereno sobre las relaciones económicas cotidianas de las gentes, que lejos está la época en que la dogmática civilista podía pretender que su construcción científica no presentara fisuras ${ }^{110}$

\footnotetext{
6 Carlos López Rodríguez, "El Derecho Comercial en el siglo XX”, en www.derechocomercial.edu.uy

7 Arturo Caumont, "Existencia y validez de los contratos. La búsqueda para la viabilidad del emprendimiento unificador del Derecho Privado Latinoamericano”. La Ley Uruguay Año VI. № 1, 51 y ss. En el mismo sentido: Carvajal Arenas, Lorena "La unificación del derecho de las obligaciones civiles y comerciales", Revista de Derecho de la Pontificia Universidad Católica de Valparaíso, XXVII. (Valparaíso, Chile. Segundo Semestre de 2006), 37-53.

8 Arturo Caumont-Santiago Miranda, “Neocentralismo y recodificación contemporánea del derecho privado: El valor del sistema central y de las reglas jurídicas de anticipación". Anuario de Derecho Civil Uruguayo. T.XLV(2014)

F.C.U Págs. 875 y ss.
} 
Israel Creimer, Unificación del Derecho Patrimonial Privado, 159-177 Carlos De Cores, "25 años que transformaron la teoría general del contrato" en El Derecho entre dos siglos T.I (Montevideo, Facultad de Derecho, UCU, 2015), 397.

10 De Cores, Carlos “25 años que transformaron..., 403-404. 
Sostiene la necesidad de recodificar dadas las nuevas situaciones y se pregunta: “¿como recodificar?”. Y contesta:

La respuesta a esta pregunta no es fácil, pero la comunidad de los juristas se esfuerza por encontrar algunos criterios orientadores".

"En primer lugar, es seguro que el sentido de una "recodificación" implicará además del tradicional el manejo de la coordinación entre la Parte general y la Parte especial del código, la incorporación de la perspectiva constitucional y de la legislación sectorial, fundamentalmente refe- rente a las relaciones de consumo"11.

Además de la tuición especial que ofrece el derecho del consumo, propone reglas para las pequeñas y medianas empresas. Como en el caso de Italia que prevé las situaciones de abuso de la dependencia económica (Ley № 192 de 1998). Tesis difundida de la doctrina europea. Este también es un tema de enorme trascendencia que debemos considerar si bus- camos realmente soluciones equitativas acordes con la realidad que vivimos. Los autores que estudian el derecho del consumidor hacen esfuerzos en este sentido ${ }^{12}$. Convendría legislarlo expresamente para evitar dudas.

Finalmente concluye De Cores:

En definitiva, la necesaria uniformización del Derecho Contractual en los ámbitos de in- tegración económica, sean ellos europeos o latinoamericanos, requiere el empleo a fondo de los marcos conceptuales de una teoría general del contrato, y el respeto del principio de libertad, sub- sidiariedad, y autonomía de la voluntad, sin perjuicio de la definición de ámbitos determinados y precisos de protección"13.

Y más adelante: "La utilidad y el valor de un esquema unitario abstracto, resulta reafirmada, en tanto ella no parece haber perdido, ni que pudiera perder, como categoría lógico-formal, su rol central en el cuadro de los actos de autonomía privada"14.

Obviamente, propone un esquema unitario.

Rivera15, por su parte, bajo el título "Codificación, Descodificación y Recodificación del Derecho Privado Argentino a la luz de la experiencia comparada", trata el tema con su habitual profundidad. Señala que en la Argentina vino por la gran cantidad de leyes especia-

11 De Cores, Carlos “25 años que transformaron..., 407.

2 Entre ellos, la Dra. Dora Szafir.

13 De Cores, Carlos “25 años que transformaron..., 422-423.

14 De Cores, Carlos “25 años que transformaron..., 425

15 Julio C. Rivera, Código Civil y Comercial de la Nación Comentado, 1. 
les que se dictaron en diversas materias atinentes, en principio, tanto al Derecho Civil como al Comercial. Algo similar sucedió en el Uruguay.

Establece que la muerte de los códigos proviene de su envejecimiento. Los cambios del siglo XX empezaron a ser muy acelerados $\mathrm{y}$, agregamos por nuestra parte, en lo que va del siglo XXI la aceleración sin duda continúa "Pero ello no implica abdicar del método si se concibe que la codificación no es en sí una meta inmóvil, sino un proceso, un conjunto esencialmente dinámico al cual constantemente se incorporan normas nuevas y se desechan las caducas y que por lo tanto exige su revisión permanente" 16 .

Este fenómeno también se ha dado en la legislación alemana ${ }^{17}$ con la BGB aprobada por el Parlamento Federal el 11 de octubre de 2001, vigente desde el

1 de enero de 2002. Estas normas surgieron después de 22 años de trabajo y están dirigidas, en las palabras de Rivera al "ciudadano de carne y hueso que lucha diariamente contra las agresiones del mercado"18. Las fuentes que se tomaron en cuenta fueron la Convención de Viena de 1980 y los

Principios de Unidroit.

\section{¿DOS CÓDIGOS?}

El objetivo de este trabajo es abogar por la unificación del derecho de las obligaciones, en un solo código.

¿Porque tenemos normas repetidas en los códigos comercial y civil? Como lo dice el Mensaje de elevación del Proyecto de Código de Comercio vigente, se incluyeron en el mis- mo, normas de Derecho Civil, porque no existía en el país un Código Civil. Este sesanciona dos años después del Código de Comercio de 1866.

Nuestro Código de Comercio surge del trabajo de dos juristas: un uruguayo, Eduardo Acevedo y un argentino, Dalmacio Vélez Sarsfield que presentaron un Código de Comercio parala Provincia de Buenos Aires en Abril de1857. Allíse dice textualmente: "En el estado actual de nuestros Códigos Civiles era imposible formar un Código de Comercio, porque las leyes comerciales suponen la existencia delas leyes civiles, son una excepción de ellas y parten de antecedentes ya prescriptos en el Derecho Común".

\footnotetext{
16 Julio C. Rivera, Código Civil y Comercial de la Nación Comentado, 17.

17 Julio C. Rivera, Código Civil y Comercial de la Nación Comentado, 19.

18 Julio C. Rivera, Código Civil y Comercial de la Nación Comentado, 19.
} 
Este Código al que hacemos referencia fue aconsejado, en nuestro país por una Comisión que se expidió en Mayo de 1861.Fue sancionado y promulgado el 26 de Mayo de 1865 por el General Flores. Luego hubo reformas al Código pero, respecto del tema que tratamos nada se tocó.

Carvajal Arenas19 nos dice que:

(...) el ideal de la unificación privatística surgirá en Europa con los 'juristas filósofos': G. Montanelli y E. Cimballi. Los juristas historiadores como Endemann y Dermburg, verán en el Derecho Comercial no sólo una categoría histórica, sino una verdadera categoría transitoria, esto es, una categoría destinadaa desaparecer"20.

En el mismo sentido se pronuncia Rivera: "Han desaparecido las diferencias entre el derecho civil y el comercial que dieron lugar a la codificación separada del siglo XIX"21.

\section{LA TESIS REVISIONISTA}

Vivante planteó en 1888 la unificación del Derecho Privado. Eso se plasmó, defi- nitivamente, en el Código Italiano de 1942 que es muy conocido en nuestro medio por la difusión de la doctrina italiana.

Broseta dice textualmente: "El Código Civil Italiano no ha realizado una unificación sustancial del Derecho privado, sino sólo la unificación de la teoría general de las obligacio- nes y de los contratos, estableciendo una única regulación para unos y otros, suprimiendo su dicotomía de régimen"22

Luego cita a Móller: "De todo ello concluye la existencia de graves síntomas en la legislación, la jurisprudencia y la doctrina que le inclinan a pensar en la conveniencia de abandonar la distinción entre Derecho Civil y Derecho Mercantil, de elaborar un amplio

\footnotetext{
${ }^{19}$ Carvajal Arenas, Lorena "La unificación del derecho..., Pág. 4

20 La autora cita a los siguientes autores: De Carvalho, Orlando, "Texeira de Freitas e a unificação do direito privado", en Roma e America. Collana di Studi Giuridici Latinoamericani 21 (Padova, Cedam, 1998), 106 y ss. La distinción del derecho civil y comercial desde el punto de vista histórico propone también Ascarelli en su obra [cit., (n. 1), p. 250]: “La distinzione tra diritto civile e commerciale si presenta perciò come un fenomeno peculiare a alcuni diritti in alcune epoche storiche e la stessa proponibilità logica di una unificazione (prescindendo della sua opportunità) torna a dimostrare che si tratta di una distinzione che non possiede un valore logico indipendente dal tempo, ma che invece riposa su situazione storiche, storicamente determinate".

${ }^{21}$ Julio C. Rivera, Código Civil y Comercial de la Nación Comentado, 27.

22 Manuel Broseta Pont, La empresa, la unificación..., 218.
} 
Código Civil general y de regular por leyes especiales ciertas materias como el Derecho de Sociedades, Seguros y el Derecho Marítimo"23.

Debe reconocerse que esto no ha pasado en otro referente muy importante del Derecho uruguayo, como el Derecho francés; sin embargo su doctrina considera la conve- niencia de unificar el Derecho privado de las obligaciones.

Tampoco se ha dado en España, donde existen normas constitucionales que lo impiden. Garrigues observa una progresiva postergación de los contratos civiles por los mercantiles ${ }^{24}$

El Código suizo de las obligaciones se remonta a $1881^{25}$ y muchos países tomaron este camino: Túnez, Marruecos, Turquía, Líbano, Polonia, Unión Soviética, Perú, Paraguay, Cuba, Holanda, Mongolia, Vietnam, Federación Rusa, Taiwán, Tailandia, China, Québec y Brasil. El Código de Quebec es fuente de muchas disposiciones del Código Civil y Comercial Argentino, sus comentaristas elogian la calidad de sus soluciones.

El sistema anglosajón es unificado desde el Siglo XVIII por el cual las reglas comer- ciales predominan frente a las civiles y subsisten normas especiales para ciertas figuras mer- cantiles. En Inglaterra se produce por primera vez la unificación. Fusión entre la merchant law y el common law. Luego hay varias leyes que lo confirman. ${ }^{26}$

\section{EL PROBLEMA URUGUAYO}

Como se dijo, en el Código de Comercio uruguayo, como no existió una legislación civil codificada se incluyeron normas propias del Derecho Civil.

Los redactores del código creían que las leyes comerciales suponen la existencia de las leyes civiles y son una excepción a ellas ${ }^{27}$. Hay una cantidad de normas que son idénticas en ambos códigos o tienen leves discrepancias.

Pérez Fontana sostuvo la derogación de esta parte del Código de Comercio por el Código Civil que es posterior en el tiempo ${ }^{28}$. Mezzera, entiende lo contrario pues el art. 2390 del Código Civil deroga la legislación anterior en cuanto a aquellas materias que "forman

\footnotetext{
${ }^{23}$ Manuel Broseta Pont, La empresa, la unificación..., 220.

${ }^{24}$ Manuel Broseta Pont, La empresa, la unificación..., 224 y 204.

${ }^{25}$ Manuel Broseta Pont, La empresa, la unificación..., 207 y ss. lo explica detalladamente.

${ }^{26}$ Manuel Broseta Pont, La empresa, la unificación..., 206 y 207.

27 Mezzera-Rippe, Curso de Derecho Comercial, T. III, Pág. 8 y ss.

28 Pérez Fontana, Sagunto. Revista Sociedades Anónimas. T. XI, Pág. 293 y ss.
} 
el objeto del presente código". Y dice que: "las leyes relativas a materias extrañas a este Código no se considerarán derogadas" y asimismo el art. 1260 dispone que: "las reglas particulares a las transacciones mercantiles en el Código de Comercio" por lo que concluye que los contratos calificados como comerciales serán regidos por el Código de Comercio.

Nuri Rodriguez y Carlos López ${ }^{29}$ contravienen lo opinado por Pérez Fontana porque el art. 2390 establece que el Código Civil deroga todas las normas anteriores "sobre las ma-terias que forman el objeto del presente Código". Asimismo los arts. 191 y 938 del Código de Comercio se remiten a las normas del Derecho Civil. El Derecho Civil es fuente del Derecho Comercial pero sólo en dónde el Código de Comercio no tiene una regulación integral.

¿Si el Código de Comercio estaría derogado no habría prueba de libros? Descartan dicha posibilidad.

El tema resulta bastante complejo y no es nuestra intención terciar en esta discusión que tiene bastante más de medio siglo.

La solución de nuestro derecho no es clara y ha dado lugar a dudas y, en éstos aspec- tos, cuánto más claridad se arroje, será mejor.

Si bien no hay dudas que el transporte y el seguro, son contratos comerciales y ellos sólo estaban regulados en el Código de Comercio, hoy ya tenemos leyes especiales -micro- sistemas- sobre estos contratos.

Hay una duplicidad de reglamentaciones en contratos, como por ejemplo, las com- praventas en que hay sólo dos diferencias menores. Lo que, no deja lugar a dudas, es que no tiene porque haber regulaciones distintas en temas como las fuentes de las obligaciones, la extinción de las mismas y otros temas afines como los que se tratan en los Títulos I, II, III y IV del Libro II del Código.

Claro que puede haber algunas particularidades del Derecho Comercial en estos te- mas como, precisamente, en cuestiones de interpretación o integración del Derecho, donde la remisión a la costumbre y a las convenciones internacionales sobre ciertos tipos de nego- cios debe preservarse. Un ejemplo claro de ello son las cartas de crédito, tan relevantes en el comercio internacional, cuyo contenido normativo vive cambios muy frecuentes, que surgen de convenciones internacionales. Los Profesores Rodríguez Olivera y López Rodríguez anali- zan exhaustivamente la cuestión. ${ }^{30}$

\footnotetext{
${ }^{29}$ Nuri Rodríguez Olivera- Carlos López Rodríguez, Manual de Derecho Comercial Uruguayo, Vol. 2 del Tomo I Pág 7 y ss.

30 Nuri Rodríguez Olivera-CarlosLópez Rodríguez, "Sobre la pretendida autonomía del Derecho Comercial" en www.derechocomercial.edu.uy
} 
Rodríguez y López comienzan por preguntarse “¿Cuándo una rama del Derecho es autónoma respecto de las restantes?" Hay diversas autonomías, la didáctica, la legislativa o la jurídica o científica, situación que se da cuando el conjunto de normas tienen principios propios.

Tanto el Derecho Civil como el Comercial son parte del Derecho privado. Como ya lo hemos señalado, dicen que la aparición del Derecho Comercial se debe a motivos históri- cos "Estrictamente el Derecho Comercial no tiene autonomía jurídica pues no tiene principios propios que lo distingan del derecfto Civil" (resaltado en el original). Citan como respaldo a Hamel y Lagarde.

Y es más, afirman: "Sería deseable que en ciertos terrenos se llegara a la unidad". Esta es exactamente la posición que sustentamos, la unificación en materia de obligaciones y contratos.

Con un Código único los problemas interpretativos se facilitan, sin perjuicio de nor- mas especiales que sólo regirían para los comerciantes o empresarios.

Esto dicho con total deliberación: ¿es el Derecho Comercial el Derecho de la empre- sa? Mucho sobre esto ya se ha dicho y lo trataremos a continuación.

\section{EL DERECHO COMERCIAL COMO DERECHO DE LAEMPRESA}

Esto ha sido afirmado por diversos autores y es la tesis del Código Italiano de 1942.

Es obvio que tal tesitura se encuentra vinculada a una determinada concepción política.

No es nuestra intención, definirnos en este tema, donde tantos y tan prominentes juristas se han pronunciado. Los argumentos a favor y en contra están explicados en diversos textos. Hay uno que lo resume todo que es el de Broseta, al cual nos remitimos y al cual hacemos referencia reiterada en este trabajo $^{31}$.

Si bien puede discutirse que exista una identidad entre el Derecho Comercial y el de la Empresa, podemos hacer, sin hesitación algunas afirmaciones.

Tomemos como definición la más sencilla: empresa es la organización de capital y trabajo. Es claro que este concepto, importado de la economía, no es una persona, ni es un bien, es una organización.

\footnotetext{
${ }^{31}$ Manuel Broseta Pont, La empresa, la unificación..., 165 y ss.
} 
La gran mayoría de la actividad mercantil se hace a través de empresas. Incluso las actividades agropecuarias, tradicionalmente consideradas civiles, tienen organización empre- saria. No advertimos porqué una fábrica de tornillos deba tener un régimen jurídico distinto a un tambo que produce leche.

¿Porqué un establecimiento pecuario que produce vacunos, que serán carne tenga un régimen distinto? No es razonable. Independientemente que muchas son sociedades que adquieren una comercialidad formal.

Incluso una asociación civil o una fundación tienen una organización empresaria.

Por eso, la ley concursal uruguaya (Ley № 18.387) establece el mismo procedimiento para todos los sujetos. Sólo dejó afuera a los consumidoresy algún caso más, por razones que nunca fueron claras.

Allí tenemos un claro caso de unificación. La misma norma, en caso de impotencia patrimonial, rige para todos los sujetos y ello simplifica y no acarrea problema alguno.

Es cierto que, por razones prácticas y políticas, algunos patrimonios, en caso de insol- vencia, tienen otros regímenes como el caso de las instituciones de intermediación financiera y los patrimonios dados en fideicomisos. Son excepciones a laregla.

Sin perjuicio de los comentarios hechos precedentemente siguiendo nuevamente a Broseta ${ }^{32}$ reiteramos e insistimos en la "la progresiva generalización de ciertas reglas e institu- ciones mercantiles" Ha habido, sin duda, un avance del Derecho Comercial sobre el civil. La razón es clara. El derecho contractual civil está, en cierto modo, estancado, mientras que el derecho comercial está en permanente evolución. Es que están empujados por la realidad empresaria que permanentemente va evolucionando, tanto como el ingenio de los empresa- rios que es casi infinito.

Hay también -aunque soterrado- un tema de orgullos. Suele señalarse que los civilis- tas invaden al Derecho Comercial.

El Derecho es uno solo y su fraccionamiento en diversas disciplinas se hace para su estudio.

En la práctica los actos y los hechos de la vida se dan comprendiendo varios tipos de normas. En un contrato comercial es posible que estén vinculadas cuestiones de derecho administrativo, tributario, de familia, etc.

Lo que puede pensarse hoy es que hay un derecho de la empresa (o de los oferentes de bienes y servicios) y un derecho del consumidor. Pero, es obvio, que los oferentes también pueden ser consumidores.

${ }^{32}$ Manuel Broseta Pont, La empresa, la unificación..., 198. 

Como dijo Kennedy en su recordado mensaje a la Unión de los años cincuenta: "todos somos consumidores".

Hay que pensar en cómo engarzar el derecho del consumidor en un Código único.

¿Debe integrarse o es mejor que tenga una ley aparte?

Los argentinos dejaron la ley pero la complementaron con normas del nuevo código.

\section{EL CÓDIGO ARGENTINO}

El Código Civil y Comercial de la Nación- Ley № 26.994 es omnicomprensivo y signi- ficó una labor muy importante. Si bien la comisión redactora estaba encabezada por Ricardo Luis Lorenzetti, Presidente de la Suprema Corte y otros juristas de nota, debe reconocerse que había un trabajo ya hecho por dos proyectos anteriores que no llegaron a entrar en vi- gencia, tal como se dijo.

Sus fundamentos básicos, se dice, entre otras cosas, están en la identidad cultural lati- noamericana en la que está la tradición romana, hispánica y francesa, la constitucionalización del derecho privado, la igualdad y la seguridad jurídica en las transacciones comerciales. El ejercicio de los derechos según el Código debe estar basado en el principio de buena fe, el reconocimiento de que el abuso de derecho es contrario a los fines del ordenamiento jurídi- co, la condena del abuso de la posición dominante en el mercado, la preservación del orden público y la condena del fraude a la ley.

Se destacan como los principales temas que aborda el nuevo código las modificacio- nes a la legislación societaria, la cuestión de la sociedad de un solo socio, la sociedad entre cónyuges, la responsabilidad de los socios de la sociedad irregular y el desarrollo del tema de la inoponibilidad de la personería jurídica. Los exégetas del nuevo código argentino han encontrado ya múltiples contradicciones en el mismo, quizás debido a la multiplicidad de autores y la dificultad de unificación y armonización de la obra.

Muchos de los temas "estrella" del Código Civil y Comercial ya están clara y eficaz- mente regulados en el derecho uruguayo.

Quizás no estuviera mal, acometer una obra monumental como la argentina, como lo propone Caumont, según mencionamos ut supra, pero ello escapa a nuestra más modesta iniciativa. Pueden revisarse con mucha utilidad en el reciente código referido las normas 
de los Libros Tercero, Cuarto y Sexto (a partir del art. 724). El Código también incursiona sustancialmente en los derechos del consumidor y en la regulación de los contratos.

Incluye además normas sobre los contratos más modernos que no están regulados en nuestros códigos y otros que están, o no, regulados por leyes especiales en nuestro país.

El nuevo código argentino nos puede servir de inspiración pues desarrolla conceptos bastante sofisticados. Sin embargo, algunos pueden ser contrarios a la tradición nacional como, por ejemplo, la recepción del principio de la lesión como un vicio (art. 332). Es un tema para pensar.

Lo que nos enseñaron como un dogma y está muy enraizado en la cultura jurídica uruguaya quizá puede ser revisado sobre todo después de los trabajos de Blengio $^{33}$, la consa- gración del principio de igualdad consagrado en el art. 8 de la Constitución nacional puede llevarnos a conclusiones diferentes a la mencionada tradición. Los juristas deben buscar la justicia, sin desconocer que la certeza en las transacciones es un valor a preservar.

Como todos los valores, están en tensión permanente entre ellos. El paso del tiempo y de los cambios sociales pueden llevar a cambiar la escala de valores.

El plazo de prescripción en principio es de cinco años (art. 2566) y, en algunos casos, plazos más breves de dos años.

En el Título Preliminar de la obra dirigida por Lorenzetti, se dice: "El Código Civil distingue el derecho de la ley”.

Este es un cambio fundamental respecto de toda una tradición anterior, que sólo se

refería a la ley, y a la función del juez, que era aplicarla exegéticamente. En cambio, ahora el panorama se amplía sobremanera, ya que no se trata sólo de la ley, sino de todas las demás fuentes: doctrina, costumbres. Asimismo, el Código recepta disposiciones contempladas en la Constitución y en los tratados internacionales, y contempla no sólo las reglas determina- das, sino también los principios y los valores. Ello permite que el Código sea el eje articula- dor de todo el sistema brindando coherencia mediante reglas y principios generales ${ }^{\prime \prime 34}$

Es una invitación a reflexionar en profundidad.

De estos principios generales podemos inferir que algunas cosas en el Uruguay están muy mal, como el del plazo de prescripción recién señalado

\footnotetext{
${ }^{33}$ Juan Blengio, "Principio de igualdad y autonomía privada. Una cuestión que se discute". Primera parte, en $A D C U$ t. XXXII p. 571 y ss. 4. "Principio de igualdad y autonomía privada. Una cuestión revisitada y que se discute. Segunda parte", en $A D C U$ XXXIII p. 481 y ss. También el multicitado Rivera, nos habla del tema a lo
} 
Israel Creimer, Unificación del Derecho Patrimonial Privado, 159-177

que agrega la cuestión del derecho empresarial, Código Civil y Comercial 37 y ss.

34 Ob. Cit. Pág. 25.

174 Revista de Derecho (UCUDAL). 2da época. Año 10. № 14 (dic. 2016). ISBN 1510-3714. ISBN on line 2393-6193 
Creemos que estos plazos son mucho más acordes con la realidad actual. ¿Seguiremos con el mismo obsceno plazo de prescripción del Código francés de hace doscientos años? Hoy en el mundo hipercomunicado nuestros plazos de prescripción son totalmente injustificados.

Hay contenidos del Código de Comercio que ya están obsoletos como la noción de acto de comercio o la regulación de los agentes auxiliares del comercio $^{35}$.

\section{¿DESAPARICIÓN DEL DERECHO MERCANTIL?}

Un autor argentino, ante la entrada en vigencia del nuevo Código Civil y Comercial de su país sostiene que se produce una esfumación del Derecho Mercantil $^{36}$. Cita a un au- tor peruano, Zegarra Mulánovich quien afirma la historicidad del Derecho Mercantil. Las fronteras entre el Derecho común y el Mercantil tienen un carácter transitorio, no puede asegurarse que el Derecho Mercantilserápermanente.

Si las exigencias del Derecho Mercantil se generalizan pierden su virtud diferenciado- ra. Alude -como tantos- a la "comercialización del derecho Privado".

Reconoce que no se advierten motivos serios, en materia de obligaciones y contratos, para someterlos a disciplinas diferentes. Cita a Ferri y a Broseta en apoyo a su tesis.

Otros autores argentinos se enfrentaron a esta posición ${ }^{37}$.

Afirman que aunque se propuso, no se incluyó en el nuevo Código normas sobre el "Estatuto del comerciante". Por ello algunos autores sostienen que el Derecho Mercantil ha perdido su autonomía legislativa, científica y funcional. En esta posición están Miguel Carlos Araya y Raúl Etcheverry.

Ahora, no solo los comerciantes tienen obligaciones contables sino que ello se extien- de a otras personas. Subsisten institutos mercantiles como el seguro y el Derecho Bancario, la tarjeta de crédito, el fideicomiso, la prenda y otros. Cuando se usan estas normas, las mismas rigen para todos los sujetos, no necesariamente a los comerciantes.

Farina invocando a Messineo, refiriéndose al Código Italiano de 1942 sostuvo qué la autonomía del Derecho Comercial debe considerarse conservada.

Ferri sostenía que sustan-

${ }^{35}$ Julio C. Rivera, Código Civil y Comercial ..., 41.

36 Gustavo Cultraro, "La esfumación del derecho mercantil" en El Nuevo Código Civil y Comercial de la 
Israel Creimer, Unificación del Derecho Patrimonial Privado, 159-177

Nación, efectos en materia Societaria y Concursal (Buenos Aires, Instituto Argentino de Derecho Comercial, 2015), 99 y ss.

37 Marcelo Barreiro-Daniel Truffat, "Aunque no lo veamos, el derecho mercantil -como el sol- siempre está (a propósito de la supuesta desaparición del mismo en el nuevo Código Civil y Comercial de la Nación Argentina)"; en prensa. 
cialmente el Derecho Comercial subsistía. Es un derecho para el mercado, la empresa o los negocios.

En definitiva, no ha desaparecido la categoría científica del Derecho Mercantil. Es que la realidad económica seguirá dando situaciones nuevas que deberán encauzarse en nor- mas o decidir si se deja librado a la autonomía de la voluntad. Tema este no fácil de definir a priori.

El Prof. Héctor Alegría en su discurso ya mencionado ha dicho textualmente:

En este punto hemos de referir solamente que participamos de la idea de la unificación codicística legislativa de las materias civil y comercial, lo que no importa desconocer el manteni- miento de cierta particularidad didáctica y técnica del derecho tradicionalmente llamado comercial, vinculado a la empresa, su institucionalidad interna sus bienes, su actividad y sus relaciones contrac- tuales o no contractuales con terceros ajenos a ella ${ }^{38}$.

\section{$\frac{10 .}{\text { COLOFÓN }}$}

Si bien la aparición del código argentino, que unifica el derecho civil y el comercial, invita a la formulación de un trabajo similar. Nuestro objetivo, al menos por ahora, es mu- cho más limitado. Se propone, simplemente, empezar a pensar en la unificación del derecho privado patrimonial en el Uruguay.

${ }^{38}$ Héctor Alegría, en sus palabras al recibir en 2013 su designación como Doctor Honoris Causa de la Facultad de Derecho de la Universidad de la República bajo el título: "Derecho Privado hoy y la innovación jurídica" . Revista de Derecho Comercial, 122. 


\section{BIBLIOGRAFÍA}

Alegría,Héctor, “Derecho Privadohoyylainnovaciónjurídica”, Revista de Derecho Comercial.

Quinta Época, Año I, № 1 (Enero-Marzo, 2016), 120.

Barreiro, Marcelo-Truffat, Daniel, "Aunque no lo veamos, el derecho mercantil como el sol- siempre está (a propósito de la supuesta desaparición del mismo en el nuevo Código Civil y Comercial de la Nación Argentina)"; en prensa.

Blengio, Juan, "Principio de igualdad y autonomía privada. Una cuestión que se discute".

Primera parte, en $A D C U$ t. XXXII p. 571 y ss. 4.

Blengio, Juan, "Principio de igualdad y autonomía privada. Una cuestión revisitada y que se discute. Segunda parte", en $A D C U$ XXXIII p. 481 y ss. También el multicitado Rivera, nos habla del tema a lo que agrega la cuestión del derecho empresarial, Código Civily Comercial37yss.

Broseta Pont, Manuel, La empresa, la unificación del derecho de las obligaciones y el derecho mercantil (Madrid, Tecnos, 1965).

Carvajal Arenas, Lorena "La unificación del derecho de las obligaciones civiles y comercia- les", Revista de Derecho de la Pontificia Universidad Católica de Valparaíso, XXVII. (Valparaíso, Chile. Segundo Semestre de 2006), 37-53.

Caumont, Arturo, "Existencia y validez de los contratos. La búsqueda para la viabilidad del emprendimiento unificador del Derecho Privado Latinoamericano", La Ley Uruguay Año VI. № 1.

Caumont, Arturo-Miranda, Santiago, "Neocentralismo y recodificación contemporánea del derecho privado: El valor del sistema central y de las reglas jurídicas de anticipación". Anuario de Derecho Civil Uruguayo. T. XLV (2014) F.C.UPágs. 875yss.

Código Civil y Comercial de la Nación Comentado, Julio César Rivera y Graciela Medina (coord..) (Buenos Aires, La Ley, ).

Creimer, Israel, "Obligaciones y Contratos Comerciales. Algunas observaciones comple- mentarias generadas por el paso del tiempo", Estudios Jurídicos. № 3 (2007), 78.

Cultraro, Gustavo, "La esfumación del derecho mercantil", El Nuevo Código Civil y Comercial de la Nación, efectos en materia Societaria y Concursal (Buenos Aires, Instituto Argentino de Derecho Comercial, 2015), 99 y ss. 
De Cores, Carlos, "25 años que transformaron la teoría general del contrato", El Derecho entre dos siglos, Miguel Tomé (coord..), T.I (Montevideo, Facultad de Derecho, UCU, 2015).

López Rodríguez, Carlos, "El Derecho Comercial en el siglo XX", en www.derechocomer- cial.edu.uy

Mezzera-Rippe, Curso de Derecho Comercial, T. III, Pág. 8 y ss.

Pérez Fontana, Sagunto. Revista Sociedades Anónimas. T. XI, Pág. 293 y ss.

Rodríguez Olivera, Nuri- López Rodríguez, Carlos, “Sobre la pretendida autonomía del Derecho Comercial" en www.derechocomercial.edu.uy

Rodríguez Olivera, Nuri- López Rodríguez, Carlos, Manual de Derecho Comercial Uruguayo, Vol. 2 del Tomo I Pág 7 y ss. 
